Newcastle Infirmary under my care, suffering from epithelioma of the under-side of the tongue of some six months' standing. 'The tongue was fixed, no glands were enlarged, but the patient was not in a favourable condition of health to make a good recovery from a severe operation. He remained in hospital for two months, and then left, returning in a few days to have the tongue removed. The connexions of the tongue in this case were divided with scissors, and the tongue cut through with the wire écraseur. Some blood was lost during the operation, and immediately afterwards the right lingual bled and had to be tied. The man rallied well, but sank from exbaustion on the seventh day. He was never able to swallow after the operation, and any attempt to do so seemed to cause him much pain. 1 was induced to use the scissors instead of the thermocautery because I hoped the resulting wound would heal sooner and be less likely to give rise to septicx'mia ; but so far as any conclusion can be drawn from a comparison of two cases only, I think the burn canses a wound which in the process of healing is less offensive and much less painful than one made with scissors. The absence of bleeding, too, during the operation, when the thermocautery is used, is an advantage, for it enables one to divide with greater exactitude what is requisite to be divided, and nothing more, and does away with any necessity for separating with the finger-in other words, of tearing - the tongue from neighbouring structures. In neither of these cases was difficulty experienced in placing the loop of wire round the base of the tongue, nor in keeping it in position. Indeed, if the tongue be sufficiently well freed to allow the wire to be placel readily in its proper position, there can be no risk of its slipping so as to cut the tongue obliquely, to prevent which the tongue is sometimes transfixed with a needle. It is true both these men died, but each was over sixty years of awe, and neither was a particularly promising case for interference. I do not know by what other means the tongue could have been removed in either of these cases with a better prospect of success, and in future I shall prefer remoring the tongue through the mouth, splitting the cheek if necessary, to any other method.

Newcastle-upon-Tyne.

\section{A METHOD OF RENOVING THE TONGUE.}

BY JAMES TAYLOR, M.R.C.S. SURGEON TO THE CHESTER GENER_L INFIRMARY.

THERE are already so many different methods of removing a diseased tongue that it would seem at first sight totally unnecessary to add another to the existing number, but the mere fact of there being so many shows that some disadvantage appertains to most or all of them, on the same principle that for any disease that more or less completely baffles treatment an innumerable number of infallible remedies are to be found-whooping-cough, for instance. It is because, I think, some of the disalvantages and difficulties of the different methods may be considerably diminished that I venture to suggest another method, the advantages of which seem to me to consist of-first, the ease with which the operation is performed; secondly, the complete severance of the tongue by a single loop of the écraseur ; thirdly, there being no necessity for the use of pins or other contrivances to ensure the loop taking a proper position. It is not even necessary to secure the tip of the tongue until near the termination of the operation, and then only to prevent the detached tongue falling back into the pharynx.

The operation is performed as follows: An incision about one-sixth of an inch long is mate through the skin only from the upper edge of the hyoid bone forwards; this incision is simpily to facilitate the passage of the needle. The forefinger of the left hand is passed along the dorsum of the tongue until the point of junction of the tongue and epiglottis is defined; the end of the forefinger is maintained at this point for the present. A strong curved needle, having a length of six inches (exclusive of handle), with eye near the point, and armed with the platinum wire of the galvanic écraseur, is passed through the little incision directly backwards in the middle line until the point is felt by the tip of the forefinger of the left hand (in its course the needle, being in the middle line, can by no possibility damagre any important tissue). Then the handle is well depressed and the needle pushed on, the point being guarded and guided by the left forefinger until it is protruded through the mouth. The wire is secured first by a pair of forceps, and then a finger is passed through the loop, the loop drawn forwards, and the needle withdrawn. We have now the loop of platinum wire traversing the base of the tonrue directly in the middle line from before back. wards, the loop brought forwards through the mouth, and the ends of the wire hanging out of the little incision in front of the throat. The next step is to pass the loop of wire over the apex and sides of the tongue, pulling the ends of the wire at the same time; we thus get the whole tongue encircled by one loop of wire. It is now advisable, but not necessary, to seize the apex of the tongue with a valsellum. Next adjust the ends of the wire to the écraseur, connect with the battery, and slowly begin to work. In from ten to fifteen minutes the wire loop will emerge from the little incision, and the now severed tongue being removed by the vulsellum from the mouth, the operation is eompleted.

If the floor of the mouth be affected, so that the loop round the tongue would pass over some diseased portion without including it, this could generally be easily remedied by a preliminary incision beyond the diseased portion, so as to form a groove for the wire loop.

This easy and simple operation I performed on July 23rd in the Chester Infirmary on a male patient, aged fifty. five, suffering from epithelioma, commencing on the left side of the tongue. The patient went on very well, and was discharged on August 20th.

Chester.

\section{NOTES OF A SMALL-POX EPIDEMIC.}

\section{By FRASER NICOLSON, L.R.C.P. EdIN.}

LATE MEDICAL OFFICER IN CIIARGE OF THE TEMPORARY SMALLPOX HOSPITAL, BROMLEY UNION, KENT.

WrThouT pretending to add anything to the history of small-pox, the following abstract of notes made during a recent epidemic in the Bromley Union may possibly give some useful hints to those who may be called upon to take a similar charge. The satisfactory results obtained, considering the proportion of confluent cases, is my only excuse for bringing these notes before the profession. The epidemic originated in a paper manufactory from a bale of filthy rags, imported from Italy, I believe, and I have heard the patients speak of poultices, bandages, and rags covered with excrement, which they had to manipulate, and which would indicate with some certainty that part of this bale, at any rate, was the refuse of a hospital ; a matter for the attention of inspectors and others.

There were forty-two cases treated between April 25th and June 29tb. Of confluent small-pox there were sixteen cases ; of discrete, fourteen ; of modified, tbirteen. Two of the confluent cases died. The chief element of success lay, I believe, in the high open bracing locality in which the temporary hospital was placed, together with the fortunate occurrence of cool dry winds during the time that the worst cases were in hospital. Those who have remarked the difference in the spirits and stamina of patients under these circumstances, as contrasted with the condition of sufferers from the disease in warm muggy weather, will understand how much there was to be thankful for in these atmospheric influences.

The modified cases may be said practically to have undergone no particular treatment. The discrete cases, varying as they did in intensity, were first treated with chlorate of potash and spirits of nitre, with milk diet, to be succeeded by broth, beef-tea, port wine, bark and ammonia, as the pustules matured and the culminating point was reached. Confluent cases were treated on precisely the same lines, with, of course, increased doses of wine, brandy, and strong liquid nourishment, together with the bark mixture (half a drachm of the aromatic spirit of anumonia, twenty minims of the spirit of chloroform, one drachm of the compound tincture of cinchona, to an ounce of water) through the period of greatest intensity, the after fever and the stage of purulency, always increasingly. I give the formula of the bark mixture as $I$ have found patients in a low state ask for it in preference to wine or brandy. For sore-throat I gave dilute nitro-hydrocbloric acid, uniformly relieved the bowels by calomel and the ordinary white mixture, and used iron and the mineral acids during convalescence. Cold sponging 